This item was submitted to Loughborough's Research Repository by the author.

Items in Figshare are protected by copyright, with all rights reserved, unless otherwise indicated.

\title{
Regio-selective substitution at the 1,3- and 6,8-positions of pyrene for the construction of small dipolar molecules
}

PLEASE CITE THE PUBLISHED VERSION

http://dx.doi.org/10.1021/acs.joc.5b02128

\section{PUBLISHER}

(C) American Chemical Society

\section{VERSION}

AM (Accepted Manuscript)

\section{PUBLISHER STATEMENT}

This work is made available according to the conditions of the Creative Commons Attribution-NonCommercialNoDerivatives 4.0 International (CC BY-NC-ND 4.0) licence. Full details of this licence are available at: https://creativecommons.org/licenses/by-nc-nd/4.0/

\section{LICENCE}

CC BY-NC-ND 4.0

\section{REPOSITORY RECORD}

Feng, Xing, Hirotsugu Tomiyasu, Jian-Yong Hu, Xian-Fu Wei, Carl Redshaw, Mark R.J. Elsegood, Lynne Horsburgh, Simon J. Teat, and Takehiko Yamato. 2019. "Regio-selective Substitution at the 1,3- and 6,8positions of Pyrene for the Construction of Small Dipolar Molecules". figshare.

https://hdl.handle.net/2134/19340. 
This document is confidential and is proprietary to the American Chemical Society and its authors. Do not copy or disclose without written permission. If you have received this item in error, notify the sender and delete all copies.

\section{Regio-selective substitution at the 1,3- and 6,8-positions of pyrene for the construction of small dipolar molecules}

\begin{tabular}{|r|l|}
\hline Journal: & The Journal of Organic Chemistry \\
\hline Manuscript ID & jo-2015-02128u.R1 \\
\hline Danuscript Type: & Article \\
\hline Complete List of Authors: & $\begin{array}{l}\text { Feng, Xing; Beijing Institute of Graphic Communication; Saga University, } \\
\text { Department of Applied Chemistry } \\
\text { Tomiyasu, Hirotsugu; Saga University, Department of Applied Chemistry } \\
\text { Hu, Jian-Yong; Shaanxi Normal University, School of Materials Science and } \\
\text { Engineering } \\
\text { Wei, Xianfu; Beijing Institute of Graphic Communication, School of } \\
\text { Materials Science and Engineering } \\
\text { Redshaw, Carl; The University of Hull, Chemistry } \\
\text { Elsegood, Mark; Loughborough University, Chemistry } \\
\text { Horsburgh, Lynne; Loughborough University, Chemistry } \\
\text { Teat, Simon; ALS, Berkeley Lab } \\
\text { Yamato, Takehiko; Saga University, Applied Chemistry }\end{array}$ \\
\hline
\end{tabular}

SCHOLARONE

Manuscripts 


\section{Regio-selective substitution at the 1,3- and 6,8-positions of} pyrene for the construction of small dipolar molecules

Xing Feng, ${ }^{\dagger \dagger}$ Hirotsugu Tomiyasu, ${ }^{\star}$ Jian-Yong Hu, ${ }^{*}$ Xianfu Wei, ${ }^{\dagger}$ Carl Redshaw, Mark R. J. Elsegood, ${ }^{\perp}$ Lynne Horsburgh, ${ }^{\perp}$ Simon J. Teat, ${ }^{\#}$ and Takehiko Yamato* ${ }^{\star}$

${ }^{\dagger}$ Beijing Institute of Graphic Communication, Beijing, 102600, P. R. China

tDepartment of Applied Chemistry, Faculty of Science and Engineering, Saga University, Honjo-machi 1, Saga 840-8502 Japan

${ }^{\S}$ School of Materials Science and Engineering, Shannxi Normal Univerity, Xi'an, 710062, Shannxi, P. R. China

"Department of Chemistry, The University of Hull, Cottingham Road, Hull, Yorkshire, HU6 7RX, UK

${ }^{\perp}$ Chemistry Department, Loughborough University, Loughborough, Leicestershire, LR11 3TU, UK

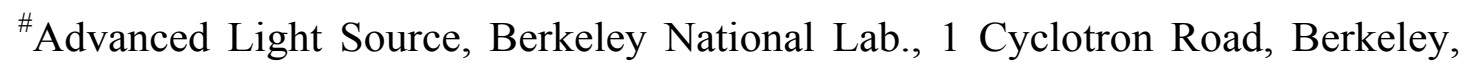
California 94720, USA

E-mail: yamatot@cc.saga-u.ac.jp, hujianyong@snnu.edu.cn

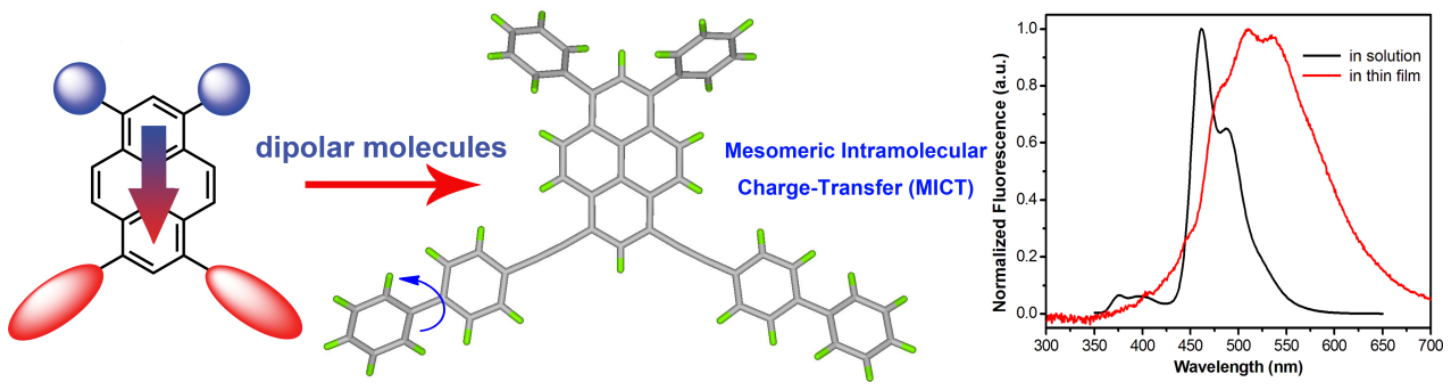

ABSTRACT: This article presents a novel asymmetrical functionalization strategy for the construction of dipolar molecules via efficient regio-selective functionalization along $\mathrm{Z}$-axis of pyrene at both the 1,3- and 6,8-positions. Three asymmetrically substituted 1,3-diphenyl-6,8-R-disubsituted pyrenes were fully 
characterized by X-ray crystallography, photophysical properties, electrochemistry, and DFT calculations.

\section{Introduction}

The construction of dipolar molecules with donor-acceptor (D-A) type structures are of interest given their potential application in organic optoelectronic devices. ${ }^{1}$ Such dipolar architectures can, via a suitable choice of the D/A units, fine-tune the electron redistribution, facilitate simultaneous manipulation of the HOMO-LUMO energy gap and the emission color by intramolecular charge transfer (ICT) ${ }^{2}$ control crystallinity, ${ }^{3}$ and be used to self-assemble molecular morphologies. ${ }^{4}$

Pyrene $^{5}$ belongs to a family of polycyclic aromatic hydrocarbons (PAHs) with a natural electron-donating and an electron-accepting role. ${ }^{6}$ Apart from other PAHs such as anthracene, ${ }^{7}$ fluorene, ${ }^{8}$ pyrene possess the equivalent activity of the sites at the 1-, 3-, 6- and 8-positions, it is different to develop an effectively rational synthetic strategy to asymmetric functionalization of pyrene. Typically, tetrabromopyrene and pyrene tetraone derivatives as key precursor were extensively utilized in the construction of PAHs for semiconductor applications, via the introduction of terminal moieties. ${ }^{5,9}$ Up to date, few examples on pyrene chemistry focus on constructing "push-pull" system and investigating the effect of the electron-donating/accepting strength to emission color of dipolar molecules, and the region-chemical relationship between donor and acceptor units.

Recently, Kim group and Lee group developed a set of tetrakissubstituted pyrenes functionalized with electron-donor and electron-acceptor moiety located at 1,6- and 
3,8-positions randomly in nature, respectively. ${ }^{10}$ However, reports focus on regio-selective substituted pyrene derivatives for bipolar materials are scant, due to the lack of straightforward strategies to modify the pyrene core. Müllen et al. reported the selective asymmetric functionalization of pyrene at the K-region for use in organic field-effect transistors via a two step chemical functionalization. ${ }^{11}$ Meanwhile, Bodwell et al. reported a regioselective synthesis of 4,5-dialkoxy-1,8-dibromopyrenes for preparing 1,8-pyrenylene-ethynylene macrocycles. ${ }^{12}$ After that, a series pyrene derivatives with D-A substituents of pyrene derivative in the K-region was presented as follows. ${ }^{13}$ Very recently, both strong donors and acceptors were introduced into the K-region and the 2,7-positions respectively, via 2,7-dibromo- and 2,7-diiodopyrene$4,5,9,10$-tetraones as the key intermediates. ${ }^{14}$ Such novel synthetic procedures at the pyrene core not only greatly enrich our knowledge of synthetic chemistry, but also stimulate further research into semiconductor materials.

Unlike the previously mentioned studies, our interest stems from exploring new effective strategies for preparing asymmetric substituted pyrene along the Z-axis to be used in high-performance electroluminescence material applications. Previously, we have released a novel approach for modifying both at the 1-, 3- and 4-, 5-, 9-, 10-positions using classical methods from 1,3-dibromo-7-tert-butylpyrene in considerable yield, ${ }^{15}$ in this case, a tert-butyl group plays a role for protecting the ring against electrophilic attack at the 6- and 8-positions. ${ }^{16}$ Herein, we further present a novel synthetic strategy to realize regio-selective substitution at the $1,3-$ and 6,8-positions of pyrene for the construction of dipolar molecules, 


\section{Results Discussion sections}

Assuming that the tert-butyl group can be removed by an effective approach, the effective approach to regio-selective substitution at the 1,3- and 6,8-positions of pyrene would be achievable. Based on our knowledge, the bulky tert-butyl group can be removed by using Nafion-H as catalyst. ${ }^{17}$ Following this inspiration, the 1,3-diphenylpyrene (3) was successfully synthesized in $85 \%$ yield from 7-tert-butyl-1,3-diphenylpyrene, which is a key step for building dipolar architectures along the Z-axis. ${ }^{18}$ The detailed synthetic procedure is illustrated in Scheme 1. Further bromination of 3 afforded 1,3-dibromo-6,8-diphenylpyrene (4) in high yield (79\%). ${ }^{19}$ Compound 4 is a novel bromide precursor used for synthesizing the desired dipolar architectures (5). This is the first example for the regio-selective, stepwise, and asymmetric substitution of pyrene at the active 1,3-, and 6,8-positions. Compared with along short axis $(4,5,9,10$-position) or at 2,7-positions, introduces dipole to pyrene as well, asymmetric functionalization both at 1,3-positions and 6,8-positions of pyrene show potential advantages, a) more artificial dipolar molecules pyrene-based would be synthesized from bromopyrene intermediations by Pd-catalyzed; b) introduce the substitutions at 1,3,6,8-positions would lead to a special influence on both the $\mathrm{S}_{2} \leftarrow \mathrm{S}_{0}$ and $\mathrm{S}_{1} \leftarrow \mathrm{S}_{0}$ transition ${ }^{18,19}$ compared with other substitution pattern, c) this strategy is beneficial to tune the band gap of the dipolar architectures to realize color control by introducing the substitution groups. For comparison, 1,3,6,8-tetraphenylpyrene (TPPy, 6$)^{20}$ was synthesized. 


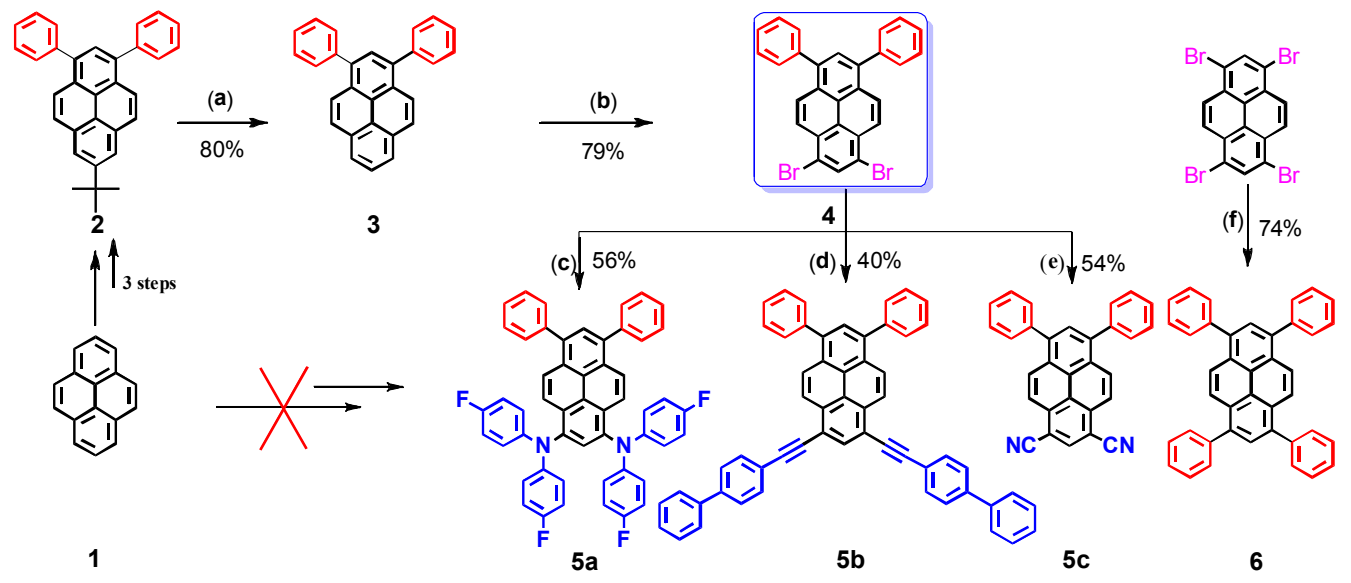

Scheme 1. Synthetic route for the preparation of 5 and 6. (a) Nafion-H, $o$-xylene, $160{ }^{\circ} \mathrm{C}, 24 \mathrm{~h}$, (b) $\mathrm{BTMABr}_{3}$ (benzyltrimethylammonium tribromide), $\mathrm{CH}_{2} \mathrm{Cl}_{2} / \mathrm{MeOH}$, room temp., $12 \mathrm{~h}$, (c) $\mathrm{NHPh}_{2} \mathrm{~F}, \mathrm{Pd}(\mathrm{OAc})_{2} /(t \mathrm{Bu})_{3} \mathrm{P} / \mathrm{K}_{2} \mathrm{CO}_{3}, o$-xylene, $160{ }^{\circ} \mathrm{C}, 24 \mathrm{~h},(\mathrm{~d})$ 4-Ethynyl-1,1'-biphenyl, [PdCl $\left.2\left(\mathrm{PPh}_{3}\right)_{2}\right], \mathrm{CuI}, \mathrm{PPh}_{3}, \mathrm{Et}_{3} \mathrm{~N} / \mathrm{DMF}(1: 1), 48 \mathrm{~h}, 100{ }^{\circ} \mathrm{C}$, (e) $\mathrm{CuCN}, \mathrm{NMP}, 48 \mathrm{~h}, 180{ }^{\circ} \mathrm{C}$, (f) phenylboronic acid, toluene, $\mathrm{Pd}\left(\mathrm{PPh}_{3}\right)_{4}, \mathrm{~K}_{2} \mathrm{CO}_{3}$, $90{ }^{\circ} \mathrm{C}, 24 \mathrm{~h}$.

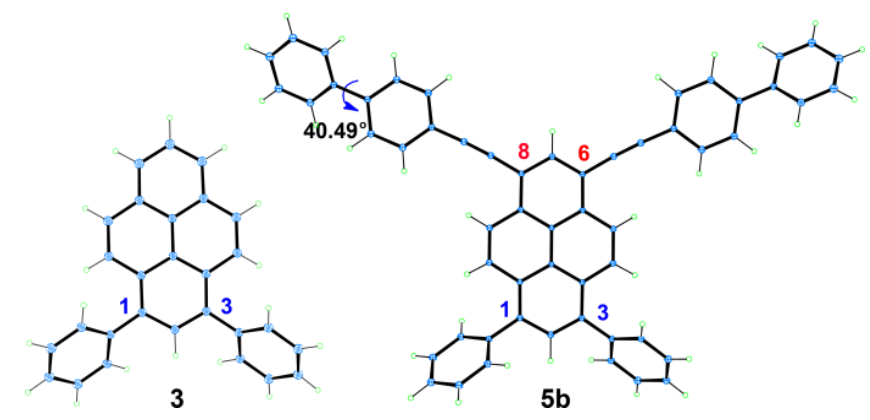

Figure 1. X-ray structures of molecules $\mathbf{3}$ and $\mathbf{5 b}$

Suitable single crystals were obtained by slow evaporation of $\mathrm{CH}_{2} \mathrm{Cl}_{2} /$ hexane solvent for $2,{ }^{16} \mathbf{5 b}(\mathrm{CCDC} 1025083)$ and $\mathbf{6}(\mathrm{CCDC} 1025084), \mathrm{CH}_{2} \mathrm{Cl}_{2} /$ acetone for $\mathbf{3}$ (CCDC 1025085) at RT. The crystal structures are presented in Figure 1 and the supporting information. Generally, the packing of the structures, and the molecular 
conformation in the crystal were influenced by short intermolecular interactions or the $\pi$-stacking present. For instance, the phenyl moieties located at the pyrene 1,3-positions in 2 , are all twisted with torsion angles in the range $45-65^{\circ}$ relative to the pyrene plane; which is arranged in a herringbone motif with a slip angle of $28^{\circ} ;{ }^{16}$ molecules of $\mathbf{3}$ are held together by strong face-to-face $\pi \cdots \pi$ stacking interactions with a shortest separation of $3.31 \AA$; the dipolar molecule $\mathbf{5 b}$ exhibited a $\pi$-stacked packing motif with $\pi-\pi$ distances in the range $3.38-3.51 \AA$; but no $\pi \cdots \pi$ stacking was observed in 6 (see SI). Interestingly, $\mathbf{5 b}$ is remarkably planar with a twist angle of approximately $40.49(3)^{\circ}$ between the adjacent rings of the biphenyl moiety, which is consistent with reported values. ${ }^{21}$ The intriguing conformations of the dipolar molecules can also lead to special optical properties.

The effect on the photophysical properties of a series of 1,3-diphenyl6,8-donor/acceptor asymmetrically substituted pyrenes 3, 5 and $\mathbf{6}$ are discussed. Figure 2 exhibits the absorption spectra of 3, 5 and $\mathbf{6}$ in dilute dichloromethane. In the D- $\pi$-A type molecules, with a strong $-\mathrm{NPh}_{2} \mathrm{~F}$ donor in $\mathbf{5 a}$, the absorption spectra exhibited a weak but broad band in the low energy absorption (375-400 nm), which indicated a charge-transfer (CT) excitation between the donor and acceptor moieties. For $\mathbf{5 b}$, a broad band around $332 \mathrm{~nm}$ is mainly due to a localized $\pi-\pi^{*}$ excitation of the biphenylethynyl group with high extinction coefficients $\left(\varepsilon=48400 \mathrm{~mol}^{-1} \mathrm{~cm}^{-1} \mathrm{~L}\right)$. In contrast, the strong acceptor group $-\mathrm{CN}$ in $\mathbf{5 c}$ has a strong influence on both the $\mathrm{S}_{1}$ $\leftarrow \mathrm{S}_{0}$ and $\mathrm{S}_{2} \leftarrow \mathrm{S}_{0}$ excitations, consistent with the large extinction coefficients with oscillator strengths. However, the compounds $\mathbf{3}$ and $\mathbf{6}$ exhibited a similar absorption 
pattern with little influence on both the $S_{1} \leftarrow S_{0}$ and $S_{2} \leftarrow S_{0}$ excitation, as reflected in the similar extinction coefficients (Table 1). Obviously, with an electron withdrawing group asymmetriclly substituted at the 6,8 -positions, the $\mathrm{S}_{1} \leftarrow \mathrm{S}_{0}$ excitation has high extinction coefficients, while the electron donors play a significant role in influencing both the $\mathrm{S}_{1} \leftarrow \mathrm{S}_{0}$ and $\mathrm{S}_{2} \leftarrow \mathrm{S}_{0}$ excitation by lowering the extinction coefficients.

Table 1. The photophysical and electrochemical properties of compounds $\mathbf{3}, \mathbf{5}$ and $\mathbf{6}$.

\begin{tabular}{|c|c|c|c|c|c|c|c|c|c|}
\hline $\mathbf{R}$ & $\begin{array}{c}\lambda_{(\mathrm{S} 1 \leftarrow \mathrm{s} 0)}{ }^{\mathrm{a}} / \underline{\varepsilon} \\
\mathrm{nm} / \mathrm{M}^{-1} \mathrm{~cm}^{-1} \mathrm{~L}\end{array}$ & $\begin{array}{c}\lambda_{(\mathrm{S} 2 \leftarrow \mathrm{S} 0)}{ }^{\mathrm{a}} / \underline{\varepsilon} \\
\mathrm{nm} / \mathrm{M}^{-1} \mathrm{~cm}^{-1} \mathrm{~L}\end{array}$ & $\begin{array}{c}\lambda_{\max A b s}^{b} \\
(\mathrm{~nm})\end{array}$ & $\begin{array}{c}\lambda_{\max P L} \\
(\mathrm{~nm})\end{array}$ & $\begin{array}{c}\text { Stokes shift } \\
\mathrm{nm}\end{array}$ & $\Phi_{f}^{c}$ & $\begin{array}{c}\mathrm{HOMO}^{\mathrm{c}}(\mathrm{IP})^{\mathrm{d}} \\
(\mathrm{eV})\end{array}$ & $\begin{array}{l}\text { LUMO } \\
(\mathrm{eV})\end{array}$ & $\begin{array}{c}\text { Energy gap } \\
(\mathrm{eV})\end{array}$ \\
\hline 3 & 357 (28000) & $286(41000)$ & 359 & $396^{\mathrm{a}}(462)^{\mathrm{b}}$ & 39 (103) & $0.27^{\mathrm{a}}(0.03)^{\mathrm{b}}$ & $-5.14(-5.83)$ & $-1.58^{e}(-2.76)^{f}$ & $3.56^{c}(3.07)^{g}$ \\
\hline $5 \mathbf{a}$ & $433(18500)$ & $285(27000)$ & 438 & 488 (469) & $55(31)$ & $0.92(0.42)$ & $-4.84(-5.70)$ & $-1.88(-3.15)$ & $2.97(2.55)$ \\
\hline $5 \mathbf{b}$ & 437 (12900) & $332(48400)$ & 455 & $462(510)$ & $25(55)$ & $0.90(0.44)$ & $-4.93(-5.77)$ & $-2.12(-3.24)$ & $2.80(2.53)$ \\
\hline $5 c$ & $411(46100)$ & $296(41000)$ & 425 & $456(537)$ & 45 (112) & $0.96(0.32)$ & $-5.90(---)$ & $-2.69(---)$ & $3.21(2.69)$ \\
\hline 6 & $394(29500)$ & $304(41200)$ & 400 & $421(464)$ & $27(64)$ & $0.87(052)$ & $-5.01(-5.76)$ & $-1.69(-2.93)$ & $3.32(2.83)$ \\
\hline \multicolumn{10}{|c|}{${ }^{a}$ Measured in dichloromethane at room temperature. ${ }^{b}$ As a thin film. ${ }^{c}$ DFT/B3LYP/6-31G* using Gaussian. ${ }^{d}$ determined using AC-3. ${ }^{e}$ LUMO $=$} \\
\hline
\end{tabular}
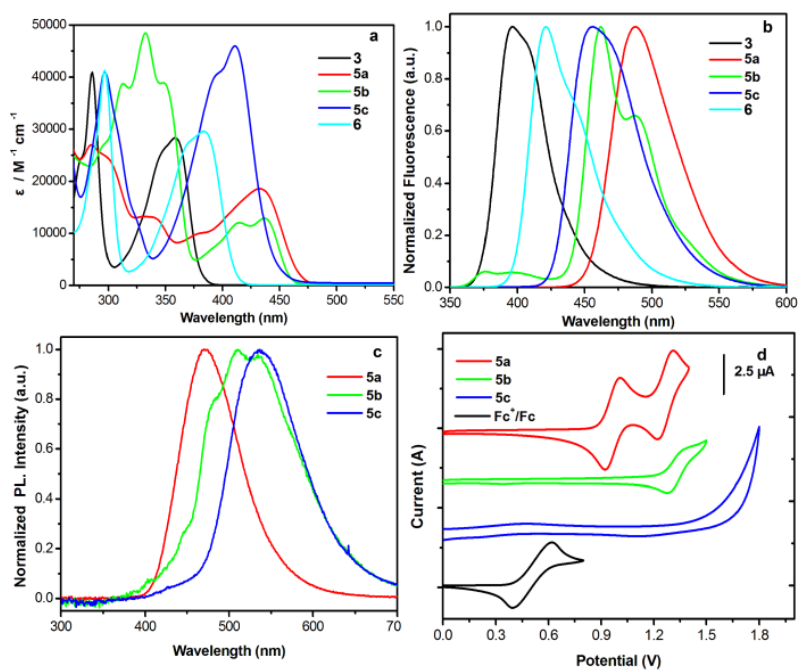

Figure 2. (a) Absorption (b) fluorescence spectra of $\mathbf{3}, \mathbf{5}$ and $\mathbf{6}$ in $\mathrm{CH}_{2} \mathrm{Cl}_{2}$, (c) PL spectra and (d) cyclic voltammograms of 5.

The emission maxima of $\mathbf{3}, \mathbf{5}$ and $\mathbf{6}$ were in the range of 396-488 $\mathrm{nm}$ in dilute dichloromethane solution with a systematic bathochromic shift following the order $\mathbf{3}<\mathbf{6}<\mathbf{5} \mathbf{c}<\mathbf{5} \mathbf{b}<\mathbf{5 a}$, suggesting that the energy gap could be fine-tuned between the ground and excited states by choosing the substituent group. The fluorescence of $\mathbf{5 a}$ 
exhibited pronounced positive solvatochromism with an intramolecular-charge-transfer (ICT) state, in which the emission wavelength display a large red shift from 464 (in cyclohexane) to 503 (in DMF) (see SI); whereas the D- $\pi$-A conjugated compound $\mathbf{5 b}$ displayed a maximum emission peak at $462 \mathrm{~nm}$ with a shoulder at $488 \mathrm{~nm}$, and contributed to an efficient mesomeric intramolecular-charge-transfer (MICT) emission, due to a twist angle $\left(40.49(3)^{\circ}\right)$ of the Franck-Condon vertical state between the diphenyl moieties. ${ }^{22}$ The dipolar molecule 5 exhibits solvent dependency of the spectroscopic and photophysical properties. The linear relationship of the Stokes shift $\left(\Delta \mathrm{V}_{\mathrm{st}}\right)$ against the solvent parameters $(\varepsilon, n)$ of $\mathbf{5}$ were determined by a Lippert-Mataga plot. ${ }^{16}$ Obviously, the MICT of the solvent polarity dependence of the fluorescence bands is weaker than for the TICT case (See SI).

Compounds $\mathbf{5 b}$ and $\mathbf{5 c}$ as films exhibited green emission and displayed a $\lambda_{\text {, film max }}$ at $510 \mathrm{~nm}$ and $537 \mathrm{~nm}$, respectively, which is significantly red shifted relative to their solutions due to the planar structure of the molecule which tends to form dimers. However, the maximum of $\mathbf{5 a}$ was blue-shifted by $19 \mathrm{~nm}$ compared with measurement in solution, due to the presence of the bulky electron-donor $-\mathrm{NPh}_{2} \mathrm{~F}$ moiety which not only plays a role in suppressing aggregation in solid, but also affects the conformation of the electronic structures, so can tune energy gap. Additionally, in solution, the dipolar molecules $\mathbf{5}$ have similar PL quantum yields ( $>$ 0.90), suggesting displays excited state ICT character. The red shifted emission with decreased quantum yields of $5(0.32-0.44)$ in the solid state attribute to the $\pi-\pi$ 
stacking interactions. Whereas $\mathbf{3}$, both in solution and in thin films, exhibited the lowest PL efficiencies, attributed to the strong molecular aggregation.

The electrochemical properties of 5 were investigated by cyclic voltammetry $(\mathrm{CV})$. The oxidation of $\mathbf{5 a}$ and $\mathbf{5 b}$ displayed a quasi-reversible oxidation process with HOMO energy levels of $5.15 \mathrm{eV}$ and $-5.51 \mathrm{eV}$, respectively. For compound $\mathbf{5 c}$, the oxidation wave was not clearly observed owing to the presence of the strongly electron-withdrawing -CN group. The result was further confirmed by photoelectron spectroscopy. The ionization potential of $\mathbf{3}, \mathbf{5 a}, \mathbf{5} \mathbf{b}$ and $\mathbf{6}$ are measured in thin film, and IP $=5.83,5.70,5.77$ and $5.76 \mathrm{eV}$ (Table 1). However, in the presence of the strong electron withdrawing group $-\mathrm{CN}$ in $\mathbf{5 c}$, the maximum IP range was greater than the instrument full-scale $(6.2 \mathrm{eV})$. The optical gap of the $\mathbf{3}, \mathbf{5}$ and $\mathbf{6}$ were calculated from the absorption spectra of their thin films at 3.07, 2.55, 2.53, 2.69 and $2.83 \mathrm{eV}$, respectively.

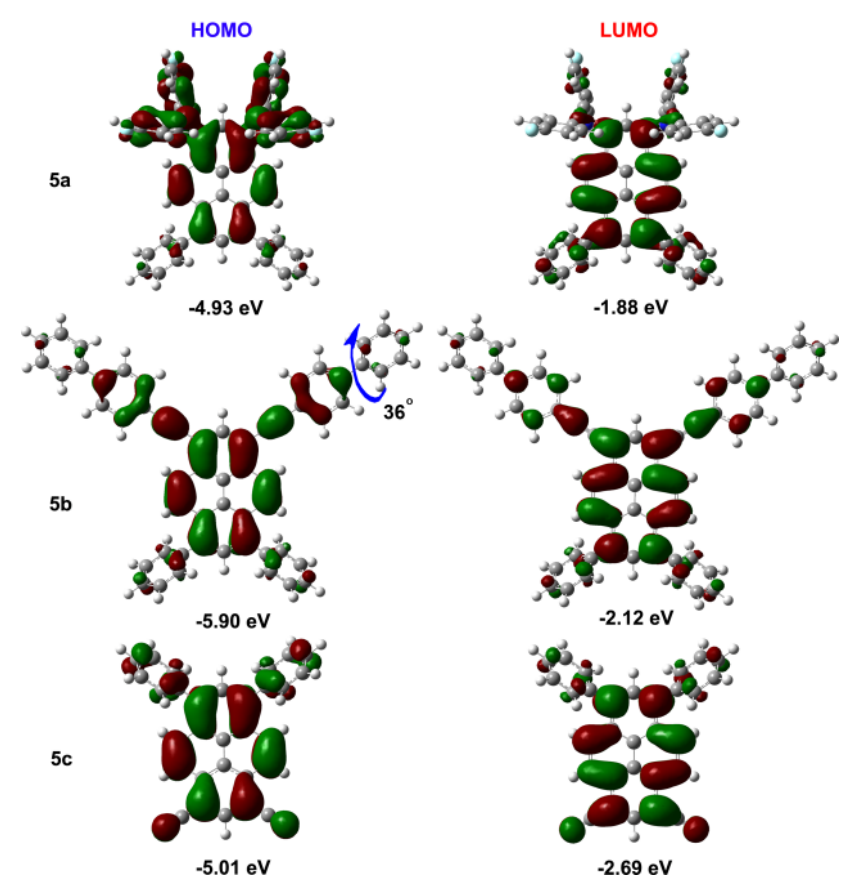

Figure 3. Computed molecular orbital plots (B3LYP/6-31G*) of 5a-c.

The energy gap was further evaluated by density functionalized theory (DFT) 
calculations. As shown in Figure 3, Obviously, due to the substituents asymmetrically located at the 1,3- and 6,8-positions, the HOMO of 5a mainly spread over the $-\mathrm{NPh}_{2} \mathrm{~F}$ moiety and the pyrene ring, whereas the LUMO extended on pyrene core and fragment phenyl ring, respectively, which implies a partial charge separation between donor (-NPh ${ }_{2} \mathrm{~F}$ moiety) and acceptor (phenyl moiety); for $\mathbf{5} \mathbf{b}$, the HOMO and LUMO were delocalized in the pyrene moiety; However, with strong acceptor $-\mathrm{CN}$ in $\mathbf{5 c}$, the HOMO located at entire molecular skeleton and the LUMO mostly existed at pyrene and cyano group. Obviously, the ICT states would be formed in molecular $\mathbf{5 a}$ and $\mathbf{5 c}$ along Z-axi with a strong donor at 1,3-positions and an acceptor at 6,8-positions. The calculated HOMO-LUMO gap of 5 is $2.97,2,81$ and 3,21 eV. In addition, the fully optimized structure of $\mathbf{5 b}$ is shown to exhibit a twist angle for C21-C22-C25-C26 of $36^{\circ}$, very close to the X-ray structure.

\section{Conclusion}

In summary, a facile synthetic strategy for the construction of dipolar architectures was explored, in which the asymmetric unit including phenyl rings and $\mathrm{NPh}_{2} \mathrm{~F} /$ biphenylethynyl/CN moieties are introduced into the 1,3-positions and 6,8-positions along the Z-axis of the pyrene core by regio-selective substitution. X-ray analysis has confirmed the novel asymmetric substitution of the pyrene core. The small dipolar molecules pyrene-based compounds possess fine ICT state between D-A units in the ground state. This article presents a revolutionary methodology for the functionalization of the pyrene core and has potential application in organic photonics. 


\section{Experimental Section}

General: All melting points are uncorrected. ${ }^{1} \mathrm{H} /{ }^{13} \mathrm{C}$ NMR spectra were recorded on a FT- NMR spectrometer $(300 \mathrm{MHz}$ and $400 \mathrm{MHz})$, respectively and referenced to 7.26 and $77.0 \mathrm{ppm}$ for chloroform-D solvent with $\mathrm{SiMe}_{4}$ as an internal reference: $J$-values are given in $\mathrm{Hz}$. IR spectra were measured for samples as $\mathrm{KBr}$ pellets in a FT-IR spectrophotometer. Mass spectra were obtained with a Mass Spectrometer at $75 \mathrm{eV}$ using a direct-inlet system. UV/Vis spectra were obtained with a UV/Vis/NIR spectrometer in various organic solvents. Fluorescence spectroscopic studies were performed in various organic solvents in a semimicro fluorescence cell (Hellma ${ }^{\circledR}$, 104F-QS, $10 \times 4 \mathrm{~mm}, 1400 \mu \mathrm{L}$ ) with a spectrophotometer. Fluorescence quantum yields were measured using absolute methods. Differential scanning calorimeter (DSC) was performed under nitrogen atmosphere at a heating rate of $10{ }^{\circ} \mathrm{C} \min ^{-1}$. Photoluminescence spectra were obtained using a luminescence spectrometer. Ionization potential was determined by atmospheric photoelectron spectroscopy. Electrochemical properties of HOMO levels were determined by Electrochemical Analyzer. The cyclic voltammetry was carried out in $0.10 \mathrm{M}$ tetrabutylammonium perchlorate in anhydrous dichloromethane and THF with a scan rate of $100 \mathrm{mV} \mathrm{s}^{1}$ at room temperature. The quantum chemistry calculation was performed on the Gaussian 03W (B3LYP/6-31G* basis set) software package. Crystallographic data of titled compound were collected by graphite monochromated Mo K $\alpha$ radiation $(\lambda=$ $0.71073 \AA$ ) in the $\omega$ scan mode. Data (excluding structure factors) on the structures reported here have been deposited with the Cambridge Crystallographic Data Centre 
with deposition numbers. CCDC 1025083-1025085 contain the supplementary crystallographic data for this paper. These data can be obtained free of charge from The Cambridge Crystallographic Data Centre via www.ccdc.cam.ac.uk/data_request/cif.

Film preparation: The thin films were prepared by solution process. Dissolve $10 \mathrm{mg}$ sample in $1 \mathrm{~mL}$ toluene solution, the solution is placed on the substrate, which is then rotated at high speed in order to spread the fluid by centrifugal force.

Material: Unless otherwise stated, all other reagents used were purchased from commercial sources and were used without further purification. The preparations of 2-tert-butylpyrene $(\mathbf{1})^{23}$ and 7-tert-butyl-1,3-dibromopyrene (2) ${ }^{16}$ were described previously.

\section{Synthesis of 7-tert-butyl-1,3-diphenylpyrene (2)}

A mixture of 7-tert-butyl-1,3-dibromopyrene (1) (200 mg, $0.5 \mathrm{mmoL})$, phenylboronic acid $(250 \mathrm{mg}, 2.0 \mathrm{mmoL})$ in toluene $(12 \mathrm{~mL})$ and ethanol $(4 \mathrm{~mL})$ at room temperature was stirred under argon, and $\mathrm{K}_{2} \mathrm{CO}_{3}(250 \mathrm{mg}, 1.8 \mathrm{mmoL})$ and $\mathrm{Pd}\left(\mathrm{PPh}_{3}\right)_{4}(70 \mathrm{mg}, 0.06$ mmol) were added. After the mixture was stirred for $30 \mathrm{~min}$ at room temperature under argon, the mixture was heated to $90{ }^{\circ} \mathrm{C}$ for $24 \mathrm{~h}$ with stirring. After cooling to room temperature, the mixture was quenched with water, extracted with $\mathrm{CH}_{2} \mathrm{Cl}_{2}(2 \times$ $30 \mathrm{~mL}$ ), washed with water and brine. The organic extracts were dried with $\mathrm{MgSO}_{4}$ and evaporated. The residue was purified by column chromatography eluting with $\left(\mathrm{CH}_{2} \mathrm{Cl}_{2} /\right.$ hexane, $\left.1: 1\right)$ to give 2 as white prisms $\left(\mathrm{CH}_{2} \mathrm{Cl}_{2} /\right.$ hexane, $\left.1: 2\right)(124 \mathrm{mg}, 63 \%)$. M.p. $186^{\circ} \mathrm{C}$; IR (KBr): $v_{\max }=2958,2900,2866,1766,1597,1484,1462,1442,1396$, 
1360, 1227, 1151, 875, 837, 810, 764, 702, 613, 503, $457 \mathrm{~cm}^{-1} ;{ }^{1} \mathrm{H}$ NMR (300 MHz, $\left.\mathrm{CDCl}_{3}\right): \delta_{\mathrm{H}}=1.59(\mathrm{~s}, 9 \mathrm{H}, t \mathrm{Bu}), 7.44-7.69(\mathrm{~m}, 10 \mathrm{H}, \mathrm{Ar}-H), 7.94\left(\mathrm{~s}, 1 \mathrm{H}\right.$, pyrene- $\left.H_{2}\right)$, $8.01\left(\mathrm{~d}, J=9.2 \mathrm{~Hz}, 2 \mathrm{H}\right.$, pyrene- $\left.H_{4,10}\right), 8.18\left(\mathrm{~d}, J=9.2 \mathrm{~Hz}, 2 \mathrm{H}\right.$, pyrene- $\left.H_{5,9}\right), 8.20 \mathrm{ppm}$ (s, 2H, pyrene- $\left.H_{6,8}\right) ;{ }^{13} \mathrm{C} \operatorname{NMR}\left(75 \mathrm{MHz}, \mathrm{CDCl}_{3}\right): \delta=149.2,141.1,137.1,131.2$, $130.6,129.0,128.3,127.8,127.6,127.2,125.3,125.1,123.4,122.2,35.2,31.9$ ppm; MS: $m / z 410.2[M]^{+}$; elemental analysis calcd. (\%) for $\mathrm{C}_{32} \mathrm{H}_{26}$ (410.2): C 93.62, $\mathrm{H}$ 6.38; found: C 93.81, H 6.19.

\section{Synthesis of 1,3-diphenylpyrene (3)}

A mixture of 1,3-diphenyl-7-tert-butylpyrene (2) (410 mg, $0.09 \mathrm{mmoL})$, Nafion-H (400 mg), and $o$-xylene $(4 \mathrm{~mL})$ were refluxed for $24 \mathrm{~h}$, and then cooled to room temperature. The solid was removed in vacuo and the mother solution collected. The crude product was purified by column chromatography using hexane as eluent to afford a yellow solid (300 mg, $85 \%$ ). M.p. $136.5-137.2{ }^{\circ} \mathrm{C} .{ }^{1} \mathrm{H}$ NMR (300 MHz, $\left.\mathrm{CDCl}_{3}\right): \delta=7.45-7.50(\mathrm{~m}, 2 \mathrm{H}, \mathrm{Ar}-H), 7.53-7.58(\mathrm{~m}, 4 \mathrm{H}, \mathrm{Ar}-H), 7.66-7.68(\mathrm{~m}, 4 \mathrm{H}$, Ar- $H), 8.00(\mathrm{~d}, J=8.8 \mathrm{~Hz}, 2 \mathrm{H}$, pyrene- $H), 8.05(\mathrm{~d}, J=2.9 \mathrm{~Hz}, 2 \mathrm{H}$, pyrene- $H), 8.16$, (s, $1 \mathrm{H}$, pyrene- $H), 8.20(\mathrm{~d}, J=2.9 \mathrm{~Hz}, 2 \mathrm{H}$, pyrene- $H)$ and $8.22(\mathrm{~s}, 1 \mathrm{H}$, pyrene- $H)$ ppm; ${ }^{13} \mathrm{C}$ NMR (100 MHz, $\left.\mathrm{CDCl}_{3}\right): \delta=141.01,137.30,131.28,130.65,129.35,128.40$, 127.93, 127.46, 127.32, 126.13, 125.27, 125.16 and $124.98 \mathrm{ppm}$. FABMS: $m / z$ : $354.22\left(\mathrm{M}^{+}\right) . \mathrm{C}_{28} \mathrm{H}_{18}$ (354.44): calcd C 94.88, H 5.12; found: C 94.85, H 5.11.

\section{Synthesis of 1,3-dibromo-6,8-diphenylpyrene (4)}

To a mixture of 1,3-diphenylpyrene $3(300 \mathrm{mg}, 0.85 \mathrm{mmol})$ in dry $\mathrm{CH}_{2} \mathrm{Cl}_{2}(30 \mathrm{~mL})$ was added dropwise a solution of $\mathrm{BTMABr}_{3}$ (benzyltrimethylammonium tribromide) 
(1.0 g, $2.6 \mathrm{mmol})$ in $\mathrm{CH}_{2} \mathrm{Cl}_{2}(10 \mathrm{~mL})$ and methanol $(5 \mathrm{~mL})$ at $0{ }^{\circ} \mathrm{C}$ for $1 \mathrm{~h}$ under argon atmosphere. The resulting mixture was allowed to slowly warm up to room temperature and stirred overnight. The reaction mixture was poured into ice-water (60 $\mathrm{mL}$ ) and neutralized with an aqueous $10 \% \mathrm{Na}_{2} \mathrm{~S}_{2} \mathrm{O}_{3}$ solution. The mixture solution was extracted with dichloromethane $(2 \times 20 \mathrm{~mL})$. The organic layer was washed with water $(2 \times 20 \mathrm{~mL})$ and saturated brine $(20 \mathrm{~mL})$, then the solution was dried $\left(\mathrm{MgSO}_{4}\right)$ and condensed under reduced pressure. The crude compound was washed with hot hexane to afford pure 1,3-dibromo-6,8-diphenylpyrene 3 (330 g, $79 \%)$ as a yellow solid. M.p. ${ }^{184-186{ }^{\circ} \mathrm{C} .}{ }^{1} \mathrm{H}$ NMR (400 MHz, $\left.\mathrm{CDCl}_{3}\right): \delta=7.49$ (m, 2H, Ar- $H$ ), 7.53-7.57 (m, 4H, Ar- $H), 7.62-7.67$ (m, 4H, Ar- $H), 8.03$ (s, 1H, pyrene- $H), 8.29(\mathrm{~d}, J$ $=9.2 \mathrm{~Hz}, 2 \mathrm{H}$, pyrene- $H), 8.33(\mathrm{~d}, J=9.6 \mathrm{~Hz}, 2 \mathrm{H}$, pyrene- $H)$ and $8.49(\mathrm{~s}, 1 \mathrm{H}$, pyrene- $H$ ) ppm; ${ }^{13} \mathrm{C}$ NMR $\left(100 \mathrm{MHz}, \mathrm{CDCl}_{3}\right): \delta=140.41,138.61,133.60,130.58$, $130.47,129.29,128.45,127.91,127.61,127.17,127.10,125.70,124.30$ and 119.24 ppm. FABMS: $m / z$ : $510.05\left(\mathrm{M}^{+}\right) . \mathrm{C}_{28} \mathrm{H}_{16} \mathrm{Br}_{2}$ (512.23): calcd C 65.65, H 3.15; found: $\mathrm{C}$ 65.35, H 3.34 .

\section{Synthesis of 1,3-bis[di(4-fluorophenyl)amino]-6,8-diphenylpyrene (5a)}

The corresponding 1,3-dibromo-6,8-diphenylpyrene (150 mg, 0.29), bis(4-fluorophenyl)amine (180 mg, $0.87 \mathrm{mmoL}), \mathrm{Pd}(\mathrm{OAc})_{2}(40 \mathrm{mg}, 0.18 \mathrm{mmoL}),(t-\mathrm{Bu})_{3} \mathrm{P}(0.05$ $\mathrm{mL})$, sodium tert-butoxide $(200 \mathrm{mg}, 2.05 \mathrm{mmoL})$, and toluene $(10 \mathrm{~mL})$ were mixed together and heated at $120{ }^{\circ} \mathrm{C}$ for $24 \mathrm{~h}$. The reaction was quenched with water $(30 \mathrm{~mL})$ and the organic layer taken into $100 \mathrm{~mL}$ of $\mathrm{CH}_{2} \mathrm{Cl}_{2}$, washed with brine solution, and dried over $\mathrm{MgSO}_{4}$. Evaporated of the solvent under vacuum resulted in a solid residue. 
The residue was adsorbed in silica gel and purified by column chromatography using hexane as eluent and recrystallization from ethyl acetate to afford the corresponding desired compound 5a as green powder (125 mg, $56 \%$ ); M.p. $161.1-162.5{ }^{\circ} \mathrm{C} .{ }^{1} \mathrm{H}$ $\operatorname{NMR}\left(400 \mathrm{MHz}, \mathrm{CDCl}_{3}\right): \delta=6.84-6.94(\mathrm{~m}, 20 \mathrm{H}, \mathrm{Ar}-H), 7.40-7.44(\mathrm{~m}, 2 \mathrm{H}, \mathrm{Ar}-H)$, $7.49(\mathrm{t}, J=7.4 \mathrm{~Hz}, 8 \mathrm{H}, \operatorname{Ar}-H), 7.53(\mathrm{~s}, 1 \mathrm{H}$, pyrene- $H), 7.56(\mathrm{~d}, J=7.2 \mathrm{~Hz}, 8 \mathrm{H}, \operatorname{Ar}-H)$, $7.94(\mathrm{~s}, 1 \mathrm{H}$, pyrene- $H), 8.00(\mathrm{~d}, J=9.6 \mathrm{~Hz}, 2 \mathrm{H}$, pyrene- $H)$ and $8.03(\mathrm{~d}, J=9.6 \mathrm{~Hz}, 2 \mathrm{H}$, pyrene- $H)) \mathrm{ppm} ;{ }^{13} \mathrm{C} \mathrm{NMR}\left(100 \mathrm{MHz}, \mathrm{CDCl}_{3}\right) \delta=159.27,156.86,144.67,144.65$, $141.56,140.63,137.89,130.47,129.97,128.48,128.34,128.04,127.40,126.55$, 125.60, 123.19, 123.11, 122.80, 116.07 and 115.85 ppm. FABMS: $m / z: 760.31\left(\mathrm{M}^{+}\right)$. $\mathrm{C}_{52} \mathrm{H}_{32} \mathrm{~F}_{4} \mathrm{~N}_{2}$ (760.82): calcd C 82.09; H 4.24, N 3.68; found: C 82.16, H 4.39 N 3.55.

\section{Synthesis of 1,3-bis[(3-biphenyl)ethynyl]-6,8-diphenylpyrene (5b)}

Mixture of 1,3-dibromo-6,8-diphenylpyrene (50 mg, $0.10 \mathrm{mmoL}), \mathrm{PdCl}_{2}\left(\mathrm{PPh}_{3}\right)_{2}(21$ $\mathrm{mg}, 0.03 \mathrm{mmoL}), \mathrm{CuI}(10 \mathrm{mg}, 0.05 \mathrm{mmoL}), \mathrm{PPh}_{3}(20 \mathrm{mg}, 0.08 \mathrm{mmoL})$, and 4-ethynyl-1,1'-biphenyl (53 mg, $0.30 \mathrm{mmoL})$ was added into a degassed solution of triethylamine $(5 \mathrm{~mL})$ and $N, N$-dimethylmethanamide $(5 \mathrm{~mL})$ under argon atmosphere. The resulting mixture was stirred at $100{ }^{\circ} \mathrm{C}$ for $48 \mathrm{~h}$. After cooling to room temperature, the mixture was quenched with water, extracted with $\mathrm{CH}_{2} \mathrm{Cl}_{2}(2 \times 30$ $\mathrm{mL}$ ), washed with water and brine. The organic extracts were dried with $\mathrm{MgSO}_{4}$ and evaporated. The residue was purified by column chromatography eluting with $\left(\mathrm{CH}_{2} \mathrm{Cl}_{2} /\right.$ hexane, $\left.2: 1\right)$ to give $\mathbf{5 b}$ as dark yellow powder $\left(\mathrm{CH}_{2} \mathrm{Cl}_{2} /\right.$ hexane, $\left.1: 2\right)(28 \mathrm{mg}$, 40 \%). M.p. $263.1-264.9{ }^{\circ} \mathrm{C} .{ }^{1} \mathrm{H}$ NMR $\left(300 \mathrm{MHz}, \mathrm{CDCl}_{3}\right): \delta=7.39$ (m, 1H, Ar- $H$ ), $7.49(\mathrm{~m}, 5 \mathrm{H}, \operatorname{Ar}-H), 7.58(\mathrm{~m}, 5 \mathrm{H}, \operatorname{Ar}-H), 7.65-7.71(\mathrm{~m}, 13 \mathrm{H}, \operatorname{Ar}-H), 7.77(\mathrm{~d}, J=8.2$ 
$\mathrm{Hz}, 4 \mathrm{H}, \operatorname{Ar}-H), 8.06(\mathrm{~s}, 1 \mathrm{H}$, pyrene- $H), 8.38(\mathrm{~d}, J=9.3 \mathrm{~Hz}, 2 \mathrm{H}$, pyrene- $H), 8.50$ (s, $1 \mathrm{H}$, pyrene- $H), 8.67(\mathrm{~d}, J=9.3 \mathrm{~Hz}, 2 \mathrm{H}$, pyrene- $H) ;{ }^{13} \mathrm{C} \mathrm{NMR}\left(100 \mathrm{MHz}, \mathrm{CDCl}_{3}\right) \delta=$ $141.92,141.19,140.64,140.31,140.06,138.57,133.31,132.90,132.08,131.98$, $130.67,129.96,128.87,128.41,128.11,127.82,127.66,127.51,127.13,127.07$, 127.00, 125.43, 122.22, 120.60, 117.65, 95.38 and 88.72 ppm. FABMS: $m / z: 706.33$ $\left(\mathrm{M}^{+}\right) . \mathrm{C}_{56} \mathrm{H}_{34}$ (706.87): calcd C 95.15, H 4.85; found: C 95.07, H 5.03.

\section{Synthesis of 1,3-dicyano-6,8-diphenylpyrene (5c)}

A mixture of 1,3-dibromo-6,8-diphenylpyrene (2) (100 mg, $0.20 \mathrm{mmoL}), \mathrm{CuCN}$ (42 $\mathrm{mg}, 0.49 \mathrm{mmoL})$, and $N$-methyl-2-pyrrolidone $(10 \mathrm{~mL})$ for $24 \mathrm{~h}$, and then cooled to room temperature. The solid was removed in vacuo and the mother solution collected. the water was added into the solution and extracted with $\mathrm{CH}_{2} \mathrm{Cl}_{2}(2 \times 30 \mathrm{~mL})$, washed with water and brine. The organic extracts were dried with $\mathrm{MgSO}_{4}$ and evaporated. The residue was purified by column chromatography eluting with $\left(\mathrm{CH}_{2} \mathrm{Cl}_{2}\right.$ /hexane, 4:1) to give $5 \mathbf{c}$ as yellow powder (43 mg, $54 \%$ ). M.p. up to $300{ }^{\circ} \mathrm{C}$. IR: ${ }^{1} \mathrm{H}$ NMR (400 $\left.\mathrm{MHz}, \mathrm{CDCl}_{3}\right): \delta=7.56-7.67(\mathrm{~m}, 10 \mathrm{H}, \mathrm{Ar}-H), 8.24(\mathrm{~s}, 1 \mathrm{H}$, pyrene- $H), 8.50(\mathrm{~d}, J=9.6$ $\mathrm{Hz}, 2 \mathrm{H}$, pyrene- $H), 8.56(\mathrm{~s}, 1 \mathrm{H}$, pyrene- $H), 8.63(\mathrm{~d}, J=8.8 \mathrm{~Hz}, 2 \mathrm{H}$, pyrene- $H) ;{ }^{13} \mathrm{C}$ $\operatorname{NMR}\left(100 \mathrm{MHz}, \mathrm{CDCl}_{3}\right) \delta=141.95,139.34,135.60,133.55,131.94,131.44,130.71$, 128.76, 128.33, 127.41, 124.34, 123.69, 123.58, 117.11 and 105.60 ppm. FABMS: $m / z$ : $404.35\left(\mathrm{M}^{+}\right) . \mathrm{C}_{30} \mathrm{H}_{16} \mathrm{~N}_{2}$ (404.46): calcd C 89.09, H 3.99; N, 6.93; found: C 89.19, H 3.69; N, 6.53.

\section{Synthesis of 1,3,6,8-tetraphenylpyrene (6)}

1,3,6,8-tetrabromopyrene (200 mg, $0.386 \mathrm{mmoL}$ ), phenylboronic acid (254 mg, 2.08 
$\mathrm{mmoL})$, and $\mathrm{Pd}\left(\mathrm{PPh}_{3}\right)_{4}(50 \mathrm{mg}, 0.04 \mathrm{mmoL})$ and aqueous $2.0 \mathrm{M} \mathrm{NaOH}(2 \mathrm{~mL})$ were mixed in a flask containing with argon saturated toluene $(10 \mathrm{~mL})$. The reaction mixture was stirred at $90{ }^{\circ} \mathrm{C}$ for $20 \mathrm{~h}$. After it was cooled to room temperature, the reaction mixture was extracted with dichloromethane $(40 \mathrm{~mL} \times 2)$. The combined organic extracts were dried with anhydrous $\mathrm{MgSO}_{4}$ and evaporated. The crude product was purified by column chromatography using hexane/dichloromethane (1:4) as eluent to provide a pale powder and recrystalized from hexane to afford 1,3,6,8-tetraphenylpyrene $\mathbf{6}$ as light yellow powder (146 mg, $74 \%$ \%. M.p $300.1-301.8{ }^{\circ} \mathrm{C} . v_{\max }(\mathrm{KBr}) / \mathrm{cm}^{-1} 2952,1608,1513,1494,1459,1286,1245,1176$, 1106, 1035, 835, 549 and 476. ${ }^{1} \mathrm{H}$ NMR (400 MHz, $\left.\mathrm{CDCl}_{3}\right): \delta=7.43-7.47(\mathrm{~m}, 2 \mathrm{H}$, Ar-H), $7.53(\mathrm{t}, J=7.6 \mathrm{~Hz}, 8 \mathrm{H}, \operatorname{Ar}-H), 7.66(\mathrm{~d}, J=8.0 \mathrm{~Hz}, 8 \mathrm{H}, \operatorname{Ar}-H), 8.00(\mathrm{~s}, 2 \mathrm{H}$, pyrene- $H$ ) and $8.17(\mathrm{~s}, 4 \mathrm{H}$, pyrene- $H) \mathrm{ppm} ;{ }^{13} \mathrm{C} \mathrm{NMR}\left(100 \mathrm{MHz}, \mathrm{CDCl}_{3}\right) \delta=141.04$, 137.22, 130.613, 129.498, 128.31, 128.10, 127.26, 125.91 and 125.28 ppm. FABMS: $m / z: 506.30\left(\mathrm{M}^{+}\right) . \mathrm{C}_{40} \mathrm{H}_{26}$ (506.63): calcd C 94.83, H 5.17; found: C 94.77, H 5.29.

\section{ASSOCIATED CONTENT}

\section{Supporting Information}

For crystallographic data in $\mathrm{CIF},{ }^{1} \mathrm{H} /{ }^{13} \mathrm{C}$ NMR data and spectral data for all new compounds etc. This material is available free of charge via the Internet at http://pubs.acs.org.

\section{AUTHOR INFORMATION}

\section{Corresponding Author}

E-mail: yamatot@cc.saga-u.ac.jp, hujianyong@snnu.edu.cn 


\section{Notes}

The authors declare no competing financial interest.

\section{ACKNOWLEDGMENT}

This work was performed under the Cooperative Research Program of "Network Joint Research Center for Materials and Devices (Institute for Materials Chemistry and Engineering, Kyushu University)". We would like to thank the EPSRC (travel grants to CR), The Royal Society of Chemistry, The Scientific Research Foundation for the Returened Overseas Chinese Scholars, State Education Ministry and The Scientific Research Common Program of Beijing Municipal Commission of Education for financial support. The Advanced Light Source is supported by the Director, Office of Science, Office of Basic Energy Sciences, of the U.S. Department of Energy under Contract No. DE-AC02-05CH11231.

\section{REFERENCES}

(1) (a) Duan, L.; Qiao, J.; Sun, Y.; Qiu, Y. Adv. Mater. 2011, 23, 1137-1144. (b) Kulkarni, A. P.; Kong, X.; Jenekhe, S. A. Adv. Funct. Mater. 2006, 16, 1057-1066. (c) Tanaka, H.; Shizu, K.; Nakanotani, H.; Adachi, C. Chem. Mater. 2013, 25, 3766-3771.

(2) Amb, C. M.; Chen, S.; Graham, K. R.; Subbiah, J.; Small, C. E.; So, F.; Reynolds, J. R. J. Am. Chem. Soc. 2011, 133, 10062-10065.

(3) (a) Wudl, F.; Smith, G.; Hufnagel, E. J. Chem. Soc., Chem. Commun. 1970, 1453-1454. (b) Torrance, J. B. Acc. Chem. Res. 1979, 12, 79-86. 
(4) (a) El-Sayed, A.; Borghetti, P.; Goiri, E.; Rogero, C.; Floreano, L.; Lovat, G.; Mowbray, D. J.; Cabellos, J. L.; Wakayama, Y.; Rubio, A.; Ortega, J. E.; Oteyza, D. G. de. ACS Nano 2013, 7, 6914-6920. (b) Sommer, M.; Huettner, S.; Thelakkat, M. Adv. Polym. Sci. 2010, 228, 123-153. (c) Szarko, J. M.; Rolczynski, B. S.; Lou, S. J.; Xu, T.; Strzalka, J.; Marks,T. J.; Yu, L.; Chen, L. X. Adv. Funct. Mater. 2014, 24, 10-26. (d) Chaskar, A.; Chen, H.-F.; Wong, K.-T. Adv. Mater. 2011, 23, 3876-3895. (e) O’Neill, M.; Kelly, S. M. Adv. Mater. 2011, 23, 566-584.

(5) (a) Figueira-Duarte, T. M.; Müllen, K. Chem. Rev. 2011, 111, 7260-7314. (b) Mateo-Alonso, A. Chem. Soc. Rev. 2014, 43, 6311-6324.

(6) Yang, S. W.; Elangovan, A.; Hwang, K. C.; Ho, T. I. J. Phys. Chem. B 2005, $109,16628-16635$.

(7) Anthony, J. E. Chem. Rev. 2006, 106, 5028-5048.

(8) (a) Elmalem, E.; Biedermann, F.; Johnson, K.; Friend, R. H.; Huck, W. T. S. J. Am. Chem. Soc. 2012, 134, 17769-17777. (b) Andrade, C. D.; Yanez, C. O.; Rodriguez, L.; Belfield, K. D. J. Org. Chem. 2010, 75, 3975-3982.

(9) Feng, X.; Hu, J.-Y.; Iwanaga, F.; Seto, N.; Redshaw, C.; Elsegood M. R. J.; Yamato, T. Org. Lett. 2013, 15, 1318-1321.

(10)(a) Lee, Y. O.; Pradhana, T.; Nob, K.; Kim, J. S. Tetrahedron 2012, 68, 1704-1711. (b) Oh, H. Y.; Lee, C.; Lee, S. Org. Electron. 2009, 10, 163-169.

(11) Zöphel, L.; Beckmann, D.; Enkelmann, V.; Chercka, D.; Rieger, R.; Müllen, K. Chem. Commun. 2011, 47, 6960-6962. 
(12) Venkataramana, G.; Dongare, P.; Dawe, L. N.; Thompson, D. W.; Zhao, Y.; Bodwell, G. Org. Lett. 2011, 13, 2240-2243.

(13) (a) Zöphel, L.; Enkelmann, V. Müllen, K. Org. Lett. 2013, 15, 804-807. (b) Keller, S. N.; Veltri, N. L.; Sutherland, T. C. Org. Lett. 2013, 15, 4798-4801.

(14) (a) More, S.; Bhosale, R.; Choudhary, S.; Mateo-Alonso, A. Org. Lett. 2012, 14, 4170-4173. (b) Kawano, S.-i.; Baumgarten, M.; Chercka, D.; Engkelmann, V.; Müllen, K. Chem. Commun. 2013, 49, 5058-5060.

(15) Feng, X.; Iwanaga, F.; Hu, J.-Y.; Tomiyasu, H.; Nakano, M.; Redshaw, C.; Elsegood M. R. J.; Yamato, T. Org. Lett. 2013, 15, 3594-3597.

(16) Feng, X.; Hu, J.-Y.; Yi, L.; Seto, N.; Tao, Z.; Redshaw, C.; Elsegood, M. R. J.; Yamato, T. Chem.-Asian J. 2012, 7, 2854-2863.

(17) Feng, X.; Hu, J.-Y.; Tomiyasu, H.; Seto, N.; Redshaw, C.; Elsegood, M. R. J.; Yamato, T. Org. Biomol. Chem. 2013, 11, 8366-8374.

(18) Crawford, A. G.; Dwyer, A. D.; Liu, Z-Q.; Steffen, A.; Beeby, A.; Pålsson, L.-O.; Tozerand, D. L.; Marder, T. B. J. Am. Chem. Soc. 2011, 133, $13349-13362$.

(19) Sato, T.; Uejima, M.; Tanaka, K.; Kajic, H.; Adachi, C. J. Mater. Chem. C, 2015, 3, 870-878.

(20) Oyamada, T.; Akiyama, S.; Yahiro, M.; Saigou, M.; Shiro, M.; Sasabe, H.; Adachi, C. Chem. Phys. Lett. 2006, 421, 295-299.

(21)Low, P. J.; Paterson, M. A.; Yufit, J. D. S.; Howard, J. A. K.; Cherryman, J. C.; Tackley, D. R.; Brook, R.; Brown, B. J. Mater. Chem. 2005, 15, 2304-2315. 
(22) Dekhtyar, M.; Rettig, W.; Weigel, W. Chem. Phys. 2008, 344, 237-250.

(23) Miura, Y.; Yamano, E.; Tanaka, A.; Yamauchi, J. J. Org. Chem. 1994, 59, 3294-3300. 